\title{
Clofazimine and dapsone compliance in leprosy
}

\author{
G A ELLARD, $*$ V K PANNIKAR, $\dagger \mathrm{K}$ JESUDASAN \\ \& M CHRISTIAN $\ddagger$ \\ * National Institute for Medical Research, London NW7 1AA, \\ England; $†$ Schieffelin Leprosy Research and Training Centre, Tamil \\ Nadu, South India
}

Accepted for publication 6 January 1988

Summary The regularity with which multibacillary patients, who were being treated with the WHO Study Group regimen in a THELEP-sponsored field trial in South India, ingested their prescribed daily clofazimine and dapsone was studied. The ingestion of clofazimine was monitored using a specially prepared formulation containing minute amounts of isoniazid as an innocuous marker. Overall drug acceptability and compliance was excellent. Approximately $75 \%$ of the prescribed daily clofazimine and dapsone doses were being ingested and it was concluded that only $5 \%$ of the patients would have benefited if their treatment had been supplemented by acedapsone injections.

There was however a marked correlation between the self-administration of the 2 drugs with the consequence that the patients at greatest risk of developing rifampicin resistance because of poor dapsone compliance were the very ones most unlikely to take their daily clofazimine treatment. The results obtained emphasize the importance of employing regimens containing high degrees of supervised drug administration, especially in areas where drug compliance is known to be poor.

\section{Introduction}

It is recommended that all multibacillary patients should be treated with a combination of rif ampicin plus dapsone plus clofazimine. ${ }^{1}$ The efficiency of two such regimens is currently being evaluated in a THELEP-sponsored field trial at the Schieffelin Leprosy Research and Training Centre in Karigiri, in the North Arcot District of Tamil Nadu in South India. ${ }^{2}$ In regimen A, supervised $600 \mathrm{mg}$ doses of rif ampicin and of clofazimine were given on each of 2 consecutive days once every 4 weeks. The patients were also given $100 \mathrm{mg}$ tablets of dapsone for daily selfadministration supplemented with intramuscular injections of $225 \mathrm{mg}$ diacetyldapsone (acedapsone) once every 8 weeks which release on average $3 \mathrm{mg}$ dapsone daily. Regimen $\mathrm{B}$ was identical to that recommended by the WHO Study Group for the routine treatment of multibacillary patients, ${ }^{1}$ consisting of monthly supervised doses of $600 \mathrm{mg}$ rif ampicin and $300 \mathrm{mg}$ clofazimine supplemented by daily doses of $50 \mathrm{mg}$ clofazimine and $100 \mathrm{mg}$ dapsone for self-administration. Treatment was to be continued for at least 2 years and until the patients became smear-negative. 
This report describes a study of the self-administration of clofazimine and dapsone by patients being treated with the WHO Study Group regimen in the field trial. It had three principal objectives; first, to compare the self-administration of dapsone and clofazimine; second, to provide a data base of individual patient compliance for future attempts to judge whether gross irregularity in drug selfadministration might result in patients eventually relapsing with rifampicin-resistant strains of Mycobacterium leprae and thirdly, to assess the proportion of patients whose dapsone compliance was so poor (those who ingested on average less than $6 \mathrm{mg}$ dapsone per day) that they would have potentially benefited from the 8-weekly acedapsone injections included in regimen A.

The unusual pharmacology of clofazimine, characterized by its steady accumulation in the body and the slow elimination of only a minute proportion of the daily dose in the urine,${ }^{3-7}$ makes it impossible to study the day-to-day self-administration of the drug directly by detecting clofazimine or its metabolites in the urine. We therefore studied its compliance using a clofazimine formulation containing minute amounts of the antituberculosis drug isoniazid as an innocuous marker for monitoring daily self-administration ${ }^{8,9}$ and assessed its ingestion by means of a simple colorimetric urine test for the isoniazid metabolites isonicotinic acid and isonicotinylglycine. ${ }^{10}$ Such a procedure is essentially capable of demonstrating whether or not the scheduled marked dose has been ingested. Dapsone compliance was assessed using a sensitive high-pressure liquid chromatographic procedure to supplement the findings obtained by the simple dapsone/creatinine ratio method.

\section{ISONIAZID-MARKED CLOFAZIMINE CAPSULES, COLLECTION OF URINE SAMPLES AND PILL COUNTING}

Capsules containing $50 \mathrm{mg}$ clofazimine plus $6 \mathrm{mg}$ isoniazid of identical appearance to standard 50 mg clofazimine capsules were specially manufactured for the study by Ciba-Geigy. The bioavailability of the isoniazid-marker component of the formulation was confirmed by demonstrating in a healthy subject (GAE) that the kinetics of the urinary excretion of isonicotinic acid and isonicotinylglycine after the oral ingestion of one of the capsules were closely similar to that demonstrated previously after the ingestion of $6 \mathrm{mg}$ doses of isoniazid in aqueous solution, capsules or tablets, ${ }^{8}$

Two pilot studies were conducted among leprosy patients in Karigiri to determine the length of time during which reliably positive urine samples would be obtained when tested by the isonicotinic acid method after the ingestion of the isoniazid-marked clof azimine capsules. In the first pilot study urine samples were obtained from 20 patients pretreatment and 1, 2, 5, 8, 10, 24 and $48 \mathrm{hr}$ after an isoniazid-marked clof azimine capsule had been ingested on an empty stomach at 9 am one morning. In the second pilot study, 10 patients ingested a single isoniazid-marked clofazimine capsule at $7 \mathrm{pm}$ one evening and urine samples were collected pretreatment and at 1, 2, 12, 14, 16, 18, 20 and $24 \mathrm{hr}$ later. Both sets of samples were randomized and recoded prior to testing.

Once each month, between their clinic visits, the patients were visited in their homes by a paramedical worker to encourage them to take self-administered treatment regularly last thing each evening. The paramedical workers also counted the patients' stocks of clofazimine capsules and dapsone tablets as a potential indicator of their compliance and retrieved any extra capsules or tablets held by the patients indicating scheduled doses that could not have been ingested.

In April 1984, towards the end of the second year of their entry into the field trial, supplies of 28 isoniazid- marked clofazimine capsules were issued in place of the standard formulation to patients being treated with the WHO Study Group regimen on the occasion of their monthly clinic visit. Approximately 1 week later urine samples were obtained between 6 and 8 am from 419 of the patients by means of surprise home visits and the patients' remaining stocks of clofazimine capsules and dapsone tablets counted. The 419 patients from whom the samples were obtained were typical of all the 488 patients currently being treated with the regimen; their ages ranged from 16 to 74 years (mean 44 years), they weighed from 32 to $68 \mathrm{~kg}$ (mean $46 \mathrm{~kg}$ ), $75 \%$ were classified as having 
lepromatous leprosy, $30 \%$ were female and $75 \%$ married. Prior to entry into the trial they had been treated for up to 20 years with dapsone monotherapy (mean 11 years).

\section{Analytical procedures}

Aliquots of urine were preserved with a crystal of thymol and stored at $0-4^{\circ} \mathrm{C}$ until shipment by air (without ref rigeration) to London for analysis. The ingestion of isoniazid was revealed by testing for the presence of the metabolites isonicotinic acid and isonicotinylglycine, positive results being indicated in non-smokers by the formation of blue or green colours within 15-30 min of reaction, and in smokers by grey or brown colours. Negative results were indicated by yellow or straw colours among non-smokers and pink or orange colours among smokers. ${ }^{9,11}$

The concentrations of dapsone plus its diazotizable metabolites $(\mu \mathrm{g} / \mathrm{ml})$ and creatinine $(\mathrm{mg} / \mathrm{ml})$ were estimated by modifications of the Bratton and Marshall and alkaline picrate procedures, respectively, and individual dapsone/creatinine $(\mathrm{D} / \mathrm{C})$ ratios calculated for each urine sample. ${ }^{12}$ The proportion of dapsone doses that had been ingested was calculated by comparing the mean $\mathrm{D} / \mathrm{C}$ ratios of the test urine samples with an appropriate mean value for fully compliant patients after allowing for the contribution from blank urine. Among samples with $\mathrm{D} / \mathrm{C}$ ratios of less than 30 , acid-labile dapsone concentrations were measured by the high pressure liquid chromatographic method previously described for estimating thiacetazone, ${ }^{13}$ but monitoring at 313 rather than 328 $\mathrm{nm}$ for increased sensitivity. Prior to the initial extraction $0.1 \mathrm{ml}$ of a $10 \mu \mathrm{g} / \mathrm{ml}$ solution of thiacetazone was added as an internal standard, acid-labile conjugates of dapsone were hydrolyzed by treating with a tenth volume of $2 \mathrm{~N} \mathrm{HCl}$ at room temperature for 15 minutes ${ }^{14}$ and the sample then neutralized with $\mathrm{NaOH}$.

\section{Results}

\section{PILOT STUDIES}

The results of the two pilot studies are summarized in Table 1. They showed that urine samples obtained up to $12 \mathrm{hr}$ after the ingestion of an isoniazid-marked clofazimine capsule gave reliably positive isonicotinic acid tests and suggested that by $36 \mathrm{hr}$ almost all of samples would have given negative results. Since all the test urine samples were obtained within $12 \mathrm{hr}$ of the time when patients should have ingested their last isoniazid-containing clofazimine capsule, it could therefore be inferred that a negative urine-test result would imply that such a dose had not been taken and that the percentage of positive urine-test results would provide a reasonable indication of the proportion of patients who had ingested their prescribed clofazimine capsule the previous day.

\section{Main compliance study}

The clinic attendance of patients on both regimens was excellent and over $90 \%$ of the patients

Table 1. Percentages of positive isonicotinic acid tests obtained among urine sample collected at varying times af ter the ingestion of isoniazid-marked clof azimine capsules

$\begin{array}{lrrrrrrrrrrrrrr}\text { Time (hours) } & 0 & 1 & 2 & 5 & 8 & 10 & 12 & 14 & 16 & 18 & 20 & 22 & 24 & 48 \\ \text { First pilot study } & 0 & 60 & 100 & 100 & 100 & 100 & - & - & - & - & - & - & 15 & 0 \\ \text { Second pilot study } & 0 & 70 & 100 & - & - & - & 100 & 90 & 90 & 70 & 50 & 40 & 20 & -\end{array}$


Table 2. Proportions of isoniazid-marked clofazimine capsules and dapsone tablets ingested

\begin{tabular}{|c|c|c|c|}
\hline & & & $\begin{array}{l}\% \text { doses } \\
\text { ingested }\end{array}$ \\
\hline $\begin{array}{l}\text { Clofazimine } \\
\text { Positive results }\end{array}$ & $\begin{array}{l}\text { Colours after testing for isonicotin } \\
\text { blue/green } \\
114 \\
\text { grey/brown* } \\
187\end{array}$ & $\begin{array}{l}\text { ic acid } \\
\text { totals } \\
301\end{array}$ & 72 \\
\hline Negative results & $\begin{array}{cc}\text { none/yellow/straw } & \text { orange/pink* } \\
41 & 77\end{array}$ & 118 & \\
\hline All & $155 \quad 264$ & 419 & \\
\hline $\begin{array}{l}\text { Dapsone } \\
\text { This study } \\
\text { Supervised } \\
\text { Untreated controls }\end{array}$ & $\begin{array}{l}\text { Number samples/patients } \\
413 \\
10 \\
10\end{array}$ & $\begin{array}{l}\mathrm{D} / \mathrm{C} \text { ratios } \dagger \\
85 \pm 2 \\
107 \pm 12 \\
7 \pm 1\end{array}$ & $78 \ddagger$ \\
\hline
\end{tabular}

* Colours indicate smokers or tobacco chewers.

$\dagger \mu \mathrm{g}$ dapsone $/ \mathrm{mg}$ creatinine (means \pm S.E.s).

$\ddagger \frac{\text { Mean test } \mathrm{D} / \mathrm{C} \text { ratios }- \text { mean blank ratios }}{\text { Mean supervised ratios }- \text { mean blank ratios }}$

collected at least $90 \%$ of their prescribed chemotherapy during the first 2 years of treatment. ${ }^{2}$ The qualitative results obtained when the 419 urine samples collected were tested by the isonicotinic acid method are summarized in Table 2. Positive results were obtained from 301 of the samples indicating that on the evening prior to the surprise collections of the urine samples about $72 \%$ of the patients had ingested their prescribed clofazimine capsule. It was apparent from the colours of the reaction products that a high proportion of the patients $(63 \%)$ were either smoking or chewing tobacco, and this was subsequently admitted by over $80 \%$ of the nicotine users identified in this way.

Dapsone/creatinine ratios could be determined for 413 of the 419 urine samples collected. The results obtained (Table 2), taken in conjunction with those from similar Indian patients who were being treated with $100 \mathrm{mg}$ daily doses of dapsone under strict supervision and from untreated controls, ${ }^{15}$ indicated that about $78 \%$ of the prescribed dapsone doses had been ingested by the field trial patients in the period immediately prior to collecting the urine samples.

The remarkable correlation between the taking of dapsone tablets and clof azimine capsules is set out in Table 3, the proportions of positive isonicotinic acid urine tests declining from $85 \%$ among those samples with $\mathrm{D} / \mathrm{C}$ ratios of over 50 to zero among those with $\mathrm{D} / \mathrm{C}$ ratios of less than 10 . On the basis of the highly correlated self-administration of dapsone and clofazimine, one could

Table 3. Correlation between the ingestion of dapsone and clof azimine

\begin{tabular}{|c|c|c|c|}
\hline $\begin{array}{l}\text { Dapsone com } \\
\text { D/C ratios }\end{array}$ & $\begin{array}{l}\text { opliance } \\
\text { Number } \\
\text { patients }\end{array}$ & $\begin{array}{c}\% \text { tablets } \\
\text { taken } \ddagger\end{array}$ & $\begin{array}{l}\text { Clofazimine compliance } \\
\text { Number }(\%) \text { positive } \\
\text { isonicotinic acid tests }\end{array}$ \\
\hline$>50$ & 334 & 93 & $284 \quad(85)$ \\
\hline $30-50$ & 30 & 33 & $7 \quad(23)$ \\
\hline $10-29 \cdot 9$ & 31 & 11 & $5 \quad(16)$ \\
\hline$<10$ & 18 & 0 & $0 \quad(0)$ \\
\hline All patients & 413 & 78 & $296 \quad(72)$ \\
\hline
\end{tabular}

$\ddagger$ See footnote Table 2 . 
conclude that the compliance of about $70 \%$ of the patients being treated with the WHO Study Group regimen was probably 'excellent' as evidenced by 284 of the 413 urine samples having D/C ratios of greater than 50 and giving positive isonicotinic acid tests. By contrast only about $10 \%$ of the patient population could be considered to be 'poor' compliars who might be taking potentially inadequate amounts of dapsone and clofazimine as evidenced by the 44 urine samples with $\mathrm{D} / \mathrm{C}$ ratios of less than 30 and negative isonicotinic acid tests. The compliance of the remaining $20 \%$ of patients was graded as 'intermediate'.

No relationship could be demonstrated between the apparent regularity with which the patients self-administered their prescribed clofazimine and dapsone treatment and their age, sex, marital status, previous duration of treatment, disease classification, extent of def ormity and whether or not they smoked.

Clofazimine-induced skin discoloration was noted after about 12 weeks treatment with the WHO Study Group regimen as compared with about 20 weeks among patients treated with the fully supervised intermittent clofazimine-containing regimen $\mathrm{A}$, and was much more marked at both 12 and 24 months in the former patients. ${ }^{2}$ There appeared to b e no discernable relationship between the patients' degree of skin pigmentation when treated with the WHO Study Group regimen and their estimated drug compliance.

Table 4 presents an analysis of the relationship between the urine test results for clofazimine and dapsone ingestion and the numbers of extra clofazimine capsules and dapsone tablets held by the patients at the time the surprise home visits were made to collect the samples. While only a quarter of the urine samples from patients with correct, fewer than correct or only one extra clofazimine capsule gave negative isonicotinic acid tests, this proportion rose to $45 \%$ among samples from patients holding 2 or 3 extra capsules $(p=0.01)$, while all the samples from patients with 4 or more additional capsules gave negative results $(p<0.001)$. Similarly the proportions of urine samples with $\mathrm{D} / \mathrm{C}$ ratios of less than 30 , indicating that at least $48 \mathrm{hr}$ had elapsed since the last dose of dapsone has been ingested, ${ }^{15}$ increased from $9 \%$ among those with fewer than 3 extra dapsone tablets to $44 \%$ among those with 3 or more additional tablets $(p<0 \cdot 001)$.

\section{Counts of patients' stocks of clof azimine capsules and dapsone tablets}

The apparent marked correlation between the extent of patient compliance assessed by objective urine tests, and the numbers of extra clofazimine capsules and dapsone tablets held by the patients when the urine samples were collected, prompted an analysis of all the information on pill counts that had been gathered as a result of the 4-weekly visits by the paramedical workers to the homes of

Table 4. Relationship between the urine test findings and numbers of extra clof azimine capsules and dapsone tablets held by the patients

\begin{tabular}{lrlrl}
\hline $\begin{array}{l}\text { Number of extra } \\
\text { capsules or tablets }\end{array}$ & $\begin{array}{c}\text { Clofazimine } \\
\text { Negative urine tests } \\
\text { proportion }(\%)^{*}\end{array}$ & $\begin{array}{c}\text { Dapsone } \\
\text { Low D/C ratios } \\
\text { proportion }(\%) \dagger\end{array}$ \\
\hline 0 & $85 / 345$ & $(25)$ & $31 / 325$ & $(10)$ \\
1 & $4 / 24$ & $(17)$ & $2 / 30$ & $(7)$ \\
2 & $9 / 19$ & $(47)$ & $2 / 28$ & $(7)$ \\
3 & $5 / 12$ & $(42)$ & $4 / 11$ & $(36)$ \\
4 or more & $13 / 13$ & $(100)$ & $7 / 14$ & $(50)$ \\
\hline
\end{tabular}

* Isonicotinic acid method.

$\dagger$ Less than $30 \mu \mathrm{g}$ dapsone per mg creatinine. 
Table 5. Correlation between numbers of extra capsules and tables held during the first 2 years of multidrug treatment and estimated patients compliance

\begin{tabular}{|c|c|c|c|}
\hline $\begin{array}{l}\text { Compliance status: } \\
\mathrm{D} / \mathrm{C} \text { ratios } \\
\text { Isonicotinic acid urine test }\end{array}$ & $\begin{array}{l}\text { Excellent } \\
\quad>50 \\
+ \text { ve }\end{array}$ & $\begin{array}{l}\text { Intermediate } \\
\text { (All others) }\end{array}$ & $\begin{array}{l}\text { Poor } \\
<10 \\
- \text { ve }\end{array}$ \\
\hline Number of patients & 250 & 65 & 28 \\
\hline Average number of medicament counts & $24 \cdot 9$ & $24 \cdot 3$ & $24 \cdot 5$ \\
\hline Occasions with extra clof azimine capsules & $3 \cdot 3 \pm 0 \cdot 2^{*}$ & $4 \cdot 0 \pm 0 \cdot 5$ & $5 \cdot 5 \pm 0 \cdot 8$ \\
\hline Occasions with extra dapsone tablets & $3 \cdot 3 \pm 0 \cdot 2$ & $3 \cdot 7 \pm 0 \cdot 5$ & $5 \cdot 3 \pm 0 \cdot 8$ \\
\hline Total number of extra clof azimine capsules & $9 \cdot 4 \pm 0 \cdot 8$ & $14 \cdot 9 \pm 2 \cdot 7$ & $23 \cdot 9 \pm 5 \cdot 6$ \\
\hline Total numbers of extra dapsone tablets & $9 \cdot 7 \pm 0 \cdot 8$ & $15 \cdot 1 \pm 3 \cdot 2$ & $25 \cdot 4 \pm 6 \cdot 0$ \\
\hline
\end{tabular}

$*$ Means \pm S.E. of mean.

the patients being treated with the Study Group Regimen. It was argued that if the pattern of compliance over the whole 2-year period was fairly consistent, then the patterns of the stocks of pills held by the patients shown to be either compliant or non-compliant at one point in time, might differ consistently over the whole period. This was indeed the case (Table 5).

Records of the stocks of medicaments were available for at least 18 of the 264-weekly scheduled home visits during the first 2 years of treatment for 343 of the patients in the compliance study. Although the numbers of extra clofazimine capsules and dapsone tablets held by the excellent compliars tended to decline during the 2 years, the pattern of extra medicaments held by the intermediate and poor compliars did not change significantly during this time. That there were highly significant differences in the patterns of pill retention between patients was shown by the marked correlations ( $r=0.51$ and $0 \cdot 56$, respectively) between the individual total numbers of extra colf azimine capsules and dapsone tablets recorded during the first and second years of treatment. The individual 2-year totals of extra clofazimine capsules and dapsone tablets in the patients' possession were also very highly correlated $(r=0 \cdot 92)$, in fact on almost half of the occasions when extra clofazimine capsules or dapsone tablets were noted, their numbers were identical.

Over the whole 2-year period, patients classified as being poorly compliant on the basis of the urine test results summarized in Table 3 , were more frequently found to have in their possession extra clofazimine capsules and dapsone tablets than the patients whose compliance had been judged to be excellent (Table 5). Similarly, the total numbers of extra capsules and tablets held by the poor compliars was approximately 2.5 times that of the excellent compliars $(p<0.001)$.

\section{Proportion of patients whose dapsone compliance was so poor that they might have benefited from acedapsone injections}

Injections of $225 \mathrm{mg}$ acedapsone once every 8 weeks deliver on average about $3 \mathrm{mg}$ dapsone per day ${ }^{16-18}$ or $3 \%$ of that ingested by fully compliant patients prescribed $100 \mathrm{mg}$ dapsone daily. It was therefore concluded that the proportion of patients whose compliance was so poor that they might have benefited from acedapsone treatment could be assessed by determining the proportion of urine samples with acid-labile dapsone/creatinine ratios of less than $6 \%$ of that of compliant patients. A pool was therefore prepared by mixing equal volumes of the 284 urine samples from the main study with $\mathrm{D} / \mathrm{C}$ ratios of greater than 50 and positive isonicotinic acid tests; i.e. from the patients designated as excellent compliars (see Table 3 ). The $\mathrm{D} / \mathrm{C}$ ratio of this pool was 100 confirming that such patients were indeed ingesting virtually all their prescribed dapsone treatment. ${ }^{15}$ Twenty-one of the 49 urine samples with original $\mathrm{D} / \mathrm{C}$ ratios of less than 30 were shown by high pressure liquid chromatography to have acid-labile dapsone/creatinine ratios of less than $6 \%$ of that of the pool 
(equivalent to an average daily intake of less than $6 \mathrm{mg}$ dapsone), suggesting that $5 \%$ of the total patient population might have benefited from twice-monthly acedapsone injections. The original $\mathrm{D} / \mathrm{C}$ ratios of their urine samples had averaged $8 \cdot 2$ (range $3 \cdot 7-15 \cdot 5$ ).

\section{Discussion}

The evidence that about $75 \%$ of the clofazimine capsules and dapsone tablets prescribed for daily self-administration by the patients being treated with the WHO Study Group regimen in the field trial were actually being ingested indicates that the overall compliance of the patients was excellent; indeed it was concluded that about $70 \%$ of the patients were probably taking almost all their prescribed treatment. These results confirm the excellent compliance of patients in Karigiri demonstrated previously when patients were being treated with dapsone monotherapy. ${ }^{19}$ Such regularity in drug self-administration is quite exceptional; in other parts of India and the rest of the world it is common to find that only about a half of the prescribed treatment is actually being ingested. ${ }^{20}$

The remarkable correlation between the self-administration of clofazimine and dapsone by the Karigiri patients accords with the excellent acceptability of clofazimine by the patients who did not find the skin pigementation it causes unduly troublesome. It was concluded that only about $10 \%$ of the patients were probably self-administering potentially inadequate amounts of dapsone and clof azimine. Furthermore, in only half these patients ( $5 \%$ of the total patient population) were the amounts of dapsone being ingested so low that the intake of the drug would have been significantly augmented by giving $225 \mathrm{mg}$ acedapsone every 8 weeks, as in regimen A. Whether, if any relapses occur, they will be found predominantly among such patients remains to be seen. At the present moment, af ter a total of over 1000 patient-years observation following the completion of treatment with each of the two regimens, not a single patient has relapsed. ${ }^{21}$

The apparent accumulation of clofazimine in the skin of patients being treated with the WHO Study Group regimen was considerably more rapid than that in patients being treated with regimen A. If the compliance of patients on the Study Group regimen throughout their first 2 years of treatment had been similar to that demonstrated at the end of the period and they had ingested about $75 \%$ of their prescribed $50 \mathrm{mg}$ daily clofazimine doses, their average monthly intake of the drug would have been about $1350 \mathrm{mg}$. Since such an amount is only slightly greater than the 1200 $\mathrm{mg}$ given under supervision as two consecutive $600 \mathrm{mg}$ doses every month to the regimen A patients, it is suggested that the absorption of $50 \mathrm{mg}$ doses of the drug may be substantially more complete than that of $600 \mathrm{mg}$ doses. Such a possibility is in accord with the very low aqueous solubility of the drug and evidence from the excretion of unchanged drug in the faeces that only about $70 \%$ of 100 $300 \mathrm{mg}$ doses of clofazimine are absorbed. ${ }^{3-5}$

The marked correlation between the numbers of extra clofazimine capsules and dapsone tablets held by the patients when the urine samples were collected for the compliance study and the urine test results was usef ul as it justified the analysis of the pill count data collected during the first 2 years of multidrug treatment to provide evidence for the overall pattern of compliance.

Such findings, however, do not justify reliance on pill counts as the only method for obtaining routine evidence of patient compliance. Thus 25 of the 44 patients classified as poor compliars, whose urine samples had dapsone/creatinine ratios of less than 30 and gave negative isonicotinic acid tests, were found to have correct numbers of capsules and tablets. Clearly, in order to satisfy the health-care staff, these patients had removed a clofazimine capsule and dapsone tablet each daybut did not ingest them. The other patients, who also failed to ingest their treatment but took less trouble to give the impression that their compliance was satisfactory, might, if pressed more strenuously, also have resorted to more efficient deception.

The most important finding of this study is the striking correlation between the taking of clofazimine and dapsone as demonstrated by the urine test results (Table 3 ) and confirmed by the 
extremely similar numbers of extra clofazimine capsules and dapsone tablets found when the patients were visited in their homes by the paramedical workers. Perhaps such an outcome might have been anticipated in view of the excellent acceptability of both clof azimine and dapsone, which provides little incentive for preferential drug ingestion. It is therefore highly likely that the marked correlation in the taking of the 2 drugs will also occur among dark-skinned patients in other parts of the world where the overall regularity of drug self-administration is much inferior to that demonstrated in Karigiri.

The saluary conclusion of this investigation is therefore that the multibacillary patients most at risk of developing rif ampicin resistance because of poor dapsone compliance, are the very ones least likely to take their prescribed clofazimine capsules when they are treated with the WHO Study Group regimen. The correct numbers of clof azimine capsules and dapsone tablets apparently held by many of the poorly compliant patients suggests that of ten the failure to take their drugs was not accidental and would therefore not have been overcome by, for example, simplifying treatment by manufacturing combined capsules containing clofazimine plus dapsone.

Since the spread of rifampicin-resistant leprosy would jeopardize all prospects of controlling leprosy with multidrug treatment, it is of the utmost importance to prevent patients relapsing with rif ampicin-resistant $H$. leprae. The results of this compliance study therefore emphasize the value of comparing the efficacy of regimens containing higher degrees of supervision, such as regimen $\mathrm{A}$ in the field trial, with that of the Study Group regimen even though among excellently compliant patients such regimens may be marginally less effecive than the Study Group regimen.

\section{Acknowledgments}

We gratef ully acknowledge the gift of the specially formulated isoniazid- containing clof azimine capsules prepared for this study by Ciba-Geigy, Basle, Switzerland, through the courtesy of Dr W Vischer. We should also like to thank Mr D R Ellard for help with analysing the urine samples and $\mathrm{Mr}$ (now Dr) T Longmore for assistance with the analysis of the data concerning the stocks of capsules and tablets and held by the patients. The investigation received financial support from the 1UNDP/World Bank/WHO Special Programme for Research and Training in Tropical Diseases.

\section{References}

1 WHO Study Group. Chemotherapy of leprosy for control programmes. WHO Technical Report Series No. 675. WHO: Geneva, 1982.

2 Pannikar VJ. Field trial of combined therapy in multibacillary leprosy. Guddiyattam Taluk, South India. M.Sc. Dissertation. University of London, 1986.

${ }^{3}$ Banerjee DK, Ellard GA, Gammon PT, Waters MFR. Some observations on the phamacology of clofazimine. Am J Trop Med Hyg, 1974; 23: 1110-5.

${ }^{4}$ Levy L. Pharmacologic studies of clofazimine. Am J Trop Med Hyg, 1974; 23: 1097-109.

5 Yawalkar SJ, Vischer W. Lamprene (clof azimine) in leprosy. Lepr Rev, 1979; 50: 135-44.

6 Feng PCC, Fenselau CC, Jacobson RR. Metabolism of clof azimine in leprosy patients. Drug Metab Dispos, 1981, 9: 521-4.

7 Lanyi Z, Dubois JP. Determination of clofazimine in human plasma by thin-layer chromatography. $J$ Chromatogr, 1982; 232: 219-23.

8 Ellard GA, Jenner PJ, Downs PA. An evaluation of the potential use of isoniazid, acetylisoniazid and isonicotinic acid for monitoring the self-administration of drugs. Br J Clin Pharmacol, 1980; 10: 369-81.

9 Stanley JNA, Pearson JMH, Ellard GA. An investigation of dapsone compliance using an isoniazid-marked formulation. Lepr Rev, 1983; 54: 317-25.

10 Ellard GA, Greenfield C. A sensitive urine-test for monitoring the ingestion of isoniazid. J Clin Path, 1977; 30: 84-7.

11 Peach H, Ellard GA, Jenner PJ, Morris RW. A simple, inexpensive urine test of smoking. Thorax, 1985; 40: $351-7$.

12 Ellard GA, Gammon PT, Helmy HS, Rees RJW. Urine tests to monitor the self-administration of dapsone by leprosy patients. Am J Trop Med Hyg, 1974; 23: 464-70. 
13 Jenner PJ. High-performance liquid chromatographic determination of thiacetazone in body fluids. $J$ Chromatogr, 1983; 276: 463-70.

14 Bushby SR, Woiwod AJ. The identification of the major diazotisable metabolite of 4:4'diaminodiphenylsulphone in rabbit urine. Biochem $J$, 1956; 63: 406-8.

15 Barton RPE, Rees RJW, McDougall AC, Ellard GA. The nose in lepromatous leprosy; Bacteriological and histopathological studies of patients treated with dapsone monotherapy for varying periods of time. Int $J$ Lepr, 1982; 50: 58-67.

${ }^{16}$ Ozawa T, Shepard CC, Karat ABA. Application of spectrophotofluorometric procedures to some problems in Mycobacterium leprae infections in mice and man treated with dapsone (DDS), diacetyl-DDS (DADDS), and di-formyl-DDS (DFD). Am J Trop Med Hyg, 1971; 20: 274-81.

17 Shepard CC, Levy L, Fasal P. The death rate of Mycobacterium leprae during treatment of lepromatous leprosy with acedapsone (DADDS). Am J Trop Med Hyg, 1972; 21: 440-5.

18 Peters JH, Murray JF, Gordon GR, Levy L, Russell DA, Scott GC, Vincin DR, Shepard CC. Acedapsone treatment of leprosy patients: response versus drug disposition. An J Trop Med Hyg, 1977; 26: 127-36.

19 Jesudasan K, George CJG, Taylor PM, Kurian PV, Job CK. An evaluation of the self-administration of DDS in Gudiyatham Taluk. Lepr India, 1976; 48 Suppl. 668-76.

${ }^{20}$ Ellard GA. Drug compliance in the treatment of leprosy. Lepr Rev, 1981; 52: 201-13.

${ }^{21}$ UNDP/World Bank/WHO Special Programme for Research and Training in Tropical Diseases. Tropical Disease Research: A Global Partnership. Maurice, Pearce NM (Eds). WHO: Geneva, 1987. 
NEWS AND NOTES

\section{Mycobacteria and human disease: Textbook by J M Grange}

This 177-page hardback, price £16.50, published by Edward Arnold Ltd, 41 Bedford Square, London WC1B 3DQ, was originally envisaged as a successor to Mycobacterial Diseases, published (by the same firm) in 1980. But, as the author says in his pref ace, there have been so many changes in recent years that it has been necessary to completely rewrite the text. The main chapter headings include: the genus Mycobacterium; the species of mycobacteria; diagnostic mycobacteriology; immunology of mycobacterial disease; epidemiology and control of mycobacterial disease; leprosy; tuberculosis; other mycobacterial diseases; therapy of mycobacterial diseases.

This is a most informative book, and what is more, it is highly readable; there are very few people in this field who would be able to cover the microbiology, immunopathology and clinical features of tuberculosis, the 'miscellaneous' mycobacterial infections, and leprosy so convincingly.

The Preface draws attention to the increasing and regrettable gap between 'high-tech' researches and those responsible for the basic care of the victims of Mycobacterial diseases. We wish this book every success in bridging the gap.

\section{Bombay Leprosy Project Report, 1976-86}

In commemoration of the Tenth Anniversary Day, 6 October 1986, this Report of Activities gives a comprehensive account of this well-known Project in Bombay and we are grateful to the Director, Dr Ganapati for sending a copy, together with a document which highlights the most important programmes in recent years (1982-86). These include: the involvement of general health services; involvement of non-health agencies; treatment; training; research; the role of slum women in the diagnosis of leprosy; health education through video films and academic work by paramedical auxiliaries. Source: Bombay Leprosy Project Administrative Office, Vidnyan Bhavan, 11, VN Purav Marg, Sion-Chunabhatti, Bombay 400 022, India.

\section{Robert Cochrane Fund for Leprosy}

The Fund, in memory of the great leprologist Robert Cochrane, is administered by the Royal Society of Tropical Medicine and Hygiene. It is to be used to finance up to three travel fellowships each year to a maximum value of $£ 1200$ each.

The intention is to enable leprosy workers to travel for practical training in field work, or in research, or to enable experienced leprologists to travel in order to provide practical clinical training in a developing country. There is no restriction on the country of origin or destination providing the above requirements are fulfilled.

Application forms are available from the Society and must be received by the Society at least 6 months ahead of the proposed trip. All applications must be sponsored by a suitable representative of the applicant's employer or study centre, and agreed by the host organization. A 2-page report on the travel/study should be submitted to the Society within 1 month of the recipients return.

Apply: Robert Cochrane Fund for Leprosy, Royal Society of Tropical Medicine and Hygiene, Manson House, 26 Portland Place, London WIN 4EY, England.

\section{Innovations in medical education, New South Wales}

From the School of Medical Education, University of New South Wales, Australia, we have received a report on a workshop forum held in 1987 on the subject of 'Implementation of Innovations in Medical Education'. The meeting was sponsored by WHO and held in the Regional Teacher Training Centre for Health Personnel in the University of New South Wales. These reports are available free of charge to bona fide applicants and frequently report activities of considerable interest to those involved in teaching and training.

\section{Acceptability of clof azimine by leprosy patients}

At the 49th Meeting of the ILEP Medical Commission in Malta, December 1987, information was presented from an enquiry sent to ILEP members about their experience with patient acceptance (or otherwise) of clofazimine. Although the total number who replied and provided quantitative data was a little disappointing, the answers received indicated that, with some exceptions, the skin colouration and other side-effects of this drug had not been a problem in practice. This accorded with a previous comment from WHO:

'During a WHO consultation on "Implementation of multidrug therapy in leprosy control", held in Geneva from 16-19 October 1985, the participants agreed that, with a few exceptions, skin discolouration which occurs in leprosy patients who are treated with clofazimine does not significantly affect patients' compliance to treatment if clof azimine is used at the dosage recommended by the WHO Study Group on Chemotherapy of Leprosy for Control Programmes (WHO Technical Report Series No. 675).' 